\title{
Espécies de Lactobacillus e seu papel na vaginose bacteriana
}

\section{Lactobacillus species and their role in bacterial vaginosis}

\author{
${ }^{1}$ Miguel Guzzo Lima \\ ${ }^{2}$ Carlos Alberto Sanches Pereira \\ ${ }^{2}$ Lara Danielle Nowak
}

1 Discente do Curso de Medicina do Centro Universitário de Volta Redonda - UniFOA.
2 Docente do Centro Universitário de Volta Redonda - UniFOA.

\section{RESUMO}

A vaginose bacteriana representa o distúrbio ginecológico mais prevalente em mulheres com idade reprodutiva e tem como etiologia principal a alteração da microbiota vaginal normal, composta predominantemente por lactobacilos que inibem o crescimento e a adesão de patógenos, fornecendo defesa local. O gênero Lactobacillus contém mais de 80 espécies, em que os predominantes, no canal vaginal da mulher em idade reprodutiva, são: $L$. crispatus $(30,1 \%)$, L. jensenii $(26,5 \%)$, L. gasseri $(22,9 \%)$ e $L$. vaginalis $(8,4 \%)$. Desses, o L. crispatus demonstrou ser o maior produtor de acido lático e o melhor protetor contra infecções. Devido as suas características benéficas, o L. crispatus poderia ser utilizado como biomarcador de saúde vaginal e como probiótico. Os lactobacilos vaginais usados como probióticos na recolonização e na manutenção da microbiota vaginal, combinados com antibióticos ou não, podem ser eficientes no tratamento e na prevenção de infecções vaginais. Entretanto, outros estudos devem ser realizados para confirmar os benefícios do uso de probióticos no tratamento da vaginose.

\section{Palavras-chave:}

Lactobacillus; vaginose; probiótico.

\begin{abstract}
Bacterial vaginosis represents the most frequent gynecological disorder in women of reproductive age and its main etiology is the alteration of the vagina normal microbiota, composed predominantly by Lactobacilli, which inhibit the growth and adhesion of pathogens providing local defense. The genre Lactobacillus contains more than 80 species, in which the prevailing in the vaginal canal of women in reproductive age, are: $L$. crispatus $(30,1 \%), L$. jensenii (26,5\%), L. gasseri $(22,9 \%)$ and L. vaginalis $(8,4 \%)$, of these, $L$. crispatus demonstrate to be the best lactic acid producer and the best against infecctions. Due to its beneficial characteristics, L. crispatus could be used as a biomarker of vaginal health, and as a probiotic. The vaginal lactobacilli used as probiotics in recolonization and maintenance of vaginal microbiota, combined with antibiotics or not, can be effective in the treatment and in the prevention of vaginal infections. However more research is needed to confirm the benefits of using probiotics to treat vaginosis.
\end{abstract}

\section{Keywords:}

Lactobacillus; vaginosis; probiotic.

\section{Como você deve citar?}

LIMA, Miguel Guzzo; PEREIRA, Carlos Alberto Sanches; NOWAK, Lara Danielle. Espécies de Lactobacillus e seu papel na vaginose bacteriana. Cadernos UniFOA, Volta Redonda, n. 28, p. 83-90, ago. 2015. 


\section{INTRODUÇÃO}

Estudos mostram que a vaginose bacteriana representa o distúrbio ginecológico mais prevalente em mulheres em idade reprodutiva (WANDERLEY et al., 2001). A microbiota normal da vagina, quando em equilíbrio, é composta predominantemente por lactobacilos que metabolizam o glicogênio das células epiteliais vaginais, promovendo a formação de acido lático que mantém um $\mathrm{pH}$ ácido $(3,8$ a 4,2), inibindo o crescimento de outras espécies bacterianas patógenas e promovendo um mecanismo de defesa local. Os lactobacilos também produzem outros fatores de proteção além dos ácidos orgânicos, como: peróxido de hidrogênio, que inibe o crescimento (principalmente) de anaeróbios, e bacteriocinas (BROLAZO et al., 2009).

Esse equilíbrio é mantido por complexas interações entre a microbiota normal, os produtos do metabolismo microbiano, o estado hormonal e a resposta imune (GIRALDO et al., 2005). Segundo (HOFFMAN et al., 2014), a microbiota vaginal normal de uma mulher em idade reprodutiva, assintomática, inclui várias espécies anaeróbias, facultativas e aeróbicas, em que as anaeróbias superam as aeróbias em proporção de 10 para 1. Qualquer alteração desse ecossistema pode modificar a prevalência de várias espécies.

A vaginose bacteriana ocorre quando há crescimento polimicrobiano maciço com a produção de sintomas genitais locais (odor e corrimento vaginal), assim como anormalidades no trato genital superior, sendo reconhecida mais como uma alteração do ecossistema vaginal do que como uma infecção causada por um germe invasor (FARO; SOPER, 2001). Clinicamente, o diagnóstico de vaginose é dado pelos critérios de Amsel e Nugent (ELEUTÉRIO, 2005; WANDERLEY et al., 2001).

Tendo em vista a alta prevalência da vaginose bacteriana nas mulheres e sua estreita relação com o desequilíbrio da microbiota normal, é importante rever o papel dos lactobacilos como promotores de mecanismos de defesa local a agentes invasores e também como regulador do crescimento anormal dos saprófitos que compõem a microbiota normal da vagina (FARO; SOPER, 2001; BROTMAN, 2011).

O presente trabalho tem como objetivo apresentar as principais espécies de lactobacilos e seu papel na vaginose bacteriana.

\section{ANATOMOFISIOLOGIA DA VAGINA}

A vagina é um tubo músculo membranoso que, superiormente, se insere em volta do colo do útero e, inferiormente, atravessa o diafragma urogenital para se abrir no períneo feminino, cujo orifício chama-se óstio da vagina. Tem função primária como órgão de cópula da mulher e secundária como canal de parto para o feto ao nascimento. Como o útero se posiciona anatomicamente em anteversoflexão, repousando sua parede anterior sobre a bexiga, faz com que a vagina tenha duas paredes, uma anterior e outra posterior (a anterior mais curta e a posterior mais longa). Estruturalmente, a vagina é constituída por uma túnica fibrosa que envolve uma túnica muscular que envolve uma malha vascular e, interiormente, é revestida por uma túnica mucosa (TESTUT; LATARJET, 1986; MOORE; DALLEY; AGUR, 2011).

A malha vascular responde pelo suporte hormonal estroprogestínico nas células da mucosa, que é revestida por epitélio escamoso, pavimentoso estratificado não queratinizado e dividido em 4 camadas: basal, parabasal, intermediaria e superficial. Nos períodos de ausência de estímulo estrogênico (infância e climatério), observa-se predomínio das células basais. Sob efeito estrogênico, as outras camadas se desenvolvem e a camada superficial traduz efeito estrogênico máximo. As células superficiais e intermediárias fornecem glicogênio que é usado pelos lactobacilos como substrato (RIBEIRO; DUTRA; GAGLIARDO, 2012). 


\section{MICROBIOTA NORMAL}

Silva e Neufeld (2006) relataram que os órgãos internos do corpo humano sadio são normalmente livres de micro-organismos, entretanto os tecidos superficiais, como a pele e membranas mucosas, após o nascimento, estão em contato constante com micro-organismos do meio ambiente e são colonizados por certas espécies que irão configurar a sua microbiota normal. Essa microbiota é adaptada e diferenciada de acordo com o sítio anatômico em que se instala, recebendo do hospedeiro um ambiente estável e favorável a sua fixação.

A microbiota normal é dividida em dois grupos: residente e transitória. Na residente, os micro-organismos são relativamente fixos e se recompõem quando alterados. Já na transitória, os micro-organismos, vindos do meio ambiente, permanecem por um determinado tempo, não se estabelecendo permanentemente. Essa microbiota residente tem o papel de manter o ecossistema microbiológico equilibrado, promovendo a saúde do hospedeiro, fornecendo a primeira linha de defesa contra patógenos, contribuindo com a digestão, a eliminação de toxinas e com a maturação do sistema imunológico. Os mecanismos de proteção promovidos pela microbiota podem impedir a adesão e o crescimento de patógenos através da competição por nutrientes, por produção de bacteriocinas, através da competição pelos receptores de ligação das células e de outros mecanismos que promovem a "interferência bacteriana" - como a acidificação do meio. Entretanto, os próprios membros da microbiota normal podem provocar doença em determinadas circunstâncias de desequilíbrio (BROOKS et al., 2012).

\subsection{Principais Membros da Microbiota Vaginal}

Logo após o nascimento, a vagina na recém-nascida é colonizada por lactobacilos oriundos do canal do parto que desaparecem quando cessa o efeito da estimulação progestogênica de origem materna, retornando, posteriormente, com a menarca e a estimulação endócrina. A progesterona aumenta o glicogênio das células epiteliais vaginais, o que provoca maior substrato disponível de carboidratos para o crescimento bacteriano, o que se altera com a variação do ciclo menstrual e com a menopausa. A presença dos lactobacilos ajuda a manter o $\mathrm{pH}$ vaginal entre 3 e 4 e a maioria da bactérias gram-negativas do trato gastrointestinal não consegue sobreviver (SILVA; NEUFELD, 2006).

O canal vaginal da mulher em idade reprodutiva possui uma microbiota normal complexa e dominada por diversas espécies de lactobacilos, onde os predominantes são: $L$. crispatus, $L$. iners, $L$. jansenii e L. gasseri. Em menor quantidade pode ser encontrada espécies de cândidas, estreptococos, Staphylococcus aureus, S. epidermidis, Enterococcus faecalis, Neisseria spp., E. coli, Proteus mirabilis, Corynebacterium spp, Peptoestreptococus sp., Prevotella, clostrídios, Gardnerella vaginalis, Micoplasma hominis, Atopobium vaginae, Veillonella spp., Ureaplasma urealyticus, Listeria e Mobiluncus spp., dentre outras (SILVA; NEUFELD, 2006; LAMONT et al., 2011; BROOKS et al., 2012).

Algumas mulheres podem ter seu micro ecossistema vaginal mantido sem o predomínio lactobacilar, podendo possuir como micro-organismos dominantes e produtores de acido lático as bactérias Atopobium vaginae, Megasphera e Leptotrichea, entretanto as bactérias Megasphera e Leptotrichea são capazes de produzir metabólitos com odor desagradável. A morfologia do Atopobium vaginae varia de cocos elípticos a bacilos curvos, ocorrendo aos pares ou em cadeias, o que torna seu reconhecimento pela bacterioscopia problemático, pois pode ser confundido com outras bactérias patogênicas; portanto o tratamento com antibióticos de mulheres assintomáticas, cujo exame mostra ausência de lactobacilos, é bastante discutível. A frequente variação de polimorfismos genéticos entre os grupos étnico-raciais pode estar relacionada a diferenças na composição desses componentes da microbiota vaginal normal (LINHARES; GIRALDO; BARACAT, 2010). 
Os micro-organismos que podem ser cultivados e identificados em laboratório representam apenas uma fração da microbiota realmente existente na vagina, visto que, quando a reação em cadeia da polimerase de largo espectro é usada para amplificar o rDNA 16s, muitas bactérias não identificadas podem ser detectadas, sendo assim o conhecimento da microbiota será constantemente atualizado (BROOKS et al., 2012).

\subsubsection{Lactobacilos}

Os lactobacilos são bactérias gram-positivas em formato de bacilo. Quando corados pelo Gram podem se apresentar também como cocobacilos, podendo ser encontrados em pares ou cadeias. 0 gênero Lactobacillus contém mais de 80 espécies. Entretanto, algumas espécies possuem características distintas, como o $L$. Iners, que é descrito como bacilos curtos gram-positivos. São fermentadores, catalase-negativos, anaeróbios facultativos ou aerotolerantes, com baixo conteúdo de bases nitrogenadas guanina e citosina. Algumas espécies constituem importantes membros da microbiota normal da vagina e raramente causam doença. Os lactobacilos recebem esse nome por produzirem ácido lático através do metabolismo fermentativo dos carboidratos (SILVA; NEUFELD, 2006; BROLAZO et al., 2009; BROOKS et al., 2012; MARTÍNEZ, 2013).

Os lactobacilos vaginais foram descritos pela primeira vez, em 1892, pelo alemão Albert Döderlein, por isso foram denominados, por muito tempo, como bacilos de Döderlein. Em 1975, foram classificados como complexo Lactobacillus acidophillus. Sua função na vagina é produzir ácido lático para acidificar o meio vaginal, produzir bacteriocinas, peróxido de hidrogênio, bissurfactantes e outras substâncias que lhe permitem competir por espaço, nutrientes e receptores com outros micro-organismos. A perda da capacidade dos lactobacilos de realizar essas funções bioquímicas proporciona a proliferação das bactérias encontradas nas mulheres com vaginose bacteriana (MARTíNEZ, 2013).

Brolazo et al. (2009) realizaram um estudo em Campinas, onde determinaram a prevalência e caracterização de espécies de lactobacilos vaginais em mulheres saudáveis com idade reprodutiva. Foram usados métodos de Multiplex PCR e RNAr 16s, nos quais 83 cepas de lactobacilos foram isoladas e identificadas, sendo as espécies predominantes L. crispatus (30,1\%), L. jensenii $(26,5 \%), L$. gasseri $(22,9 \%)$ e $L$. vaginalis $(8,4 \%)$. As outras espécies isoladas foram $L$. delbrueckii, $L$. fermentum, $L$ reuteri, L. rhamnosus, L. mucosae e L. salivarius.

Outro estudo realizado em mulheres americanas não sintomáticas e em idade reprodutiva de diferentes grupos étnicos (brancas, asiáticas, negras e hispânicas) demonstrou diferenças do predomínio lactobacilar no ecossistema vaginal, onde as espécies mais prevalentes foram: $L$. crispatus, $L$. iners, L. jansenii e L. gasseri. A microbiota vaginal dominada por lactobacilos foi encontrada em $80,2 \%$, nas asiáticas; $89,7 \%$, nas brancas; $59,6 \%$, nas hispânicas e $61,9 \%$, nas negras. 0 motivo dessa diferença entre os grupos étnicos é desconhecido, entretanto é especulado que essa diferença na comunidade vaginal pode ser determinada por particularidades genéticas entre os hospedeiros. Outra particularidade genética se encontra nessas espécies de lactobacilos mais prevalentes no sítio vaginal, onde apresentam um número menor de genes que as outras espécies de lactobacilos menos prevalentes. Isso sugere que essas espécies apresentam alguma forma de adaptação ao seu hospedeiro. 0 autor compara essa característica às espécies de micro-organismos que dependem completamente de um hospedeiro para sobreviver, como os intracelulares (RAVEL et al., 2011; SOARES et al., 2014).

Os lactobacilos vaginais podem ser usados como probióticos na recolonização e na manutenção da microbiota vaginal. A administração de lactobacilos ( $10^{9} \mathrm{UFC}$ ) por via oral ou intra vaginal, em combinação com antibióticos ou não, pode ser eficiente no tratamento e na prevenção de infecções vaginais. 
Estudos que utilizam lactobacilos para tratar vaginoses têm demonstrado o aumento da cura e a redução de recorrência, quando associado à antibioticoterapia. Os lactobacilos exercem também efeito profilático em mulheres saudáveis, podendo ser usados por longo período sem demonstrar efeito adverso. A melhor via de administração de probióticos com lactobacilos é a intravaginal, entretanto alguns autores recomendam a via oral, sendo esta mais lenta. Entretanto, outros estudos serão necessários para confirmar os benefícios do uso de probióticos no tratamento da vaginose (MASTROMARINO; VITALI; MOSCA, 2013).

Estudos demonstram que a microbiota vaginal colonizada predominantemente pelo $L$. crispatus implica em um microambiente mais ácido do que quando outras espécies de lactobacilos dominam, sugerindo que o $L$. crispatus é um dos maiores produtores de acido lático no ecossistema vaginal, fazendo com que sua prevalência reflita em um efeito, significantemente, mais protetor contra infecções. A rápida detecção de lactobacilos vaginais como o $L$. crispatus por métodos moleculares poderia determinar a sua utilização como um biomarcador de saúde vaginal e, também, uma vez que essa espécie é frequentemente isolada em sítios vaginais saudáveis, possui um grande potencial de ser utilizado como probiótico no tratamento e na prevenção da vaginose (HERMMERLING et al., 2010; RAVEL et al., 2011; MACHADO; JEFFERSON; CERCA, 2013; PETROVA et al., 2015).

\section{VAGINOSE BACTERIANA}

Quando ocorre diminuição dos lactobacilos, há diminuição da acidez no meio vaginal (para um $\mathrm{pH}$ maior do que 4,5), favorecendo a proliferação de micro-organismos aeróbicos e anaeróbicos com produção, por essas bactérias, de aminas voláteis que liberam "cheiro de peixe" em situações de maior alcalinização do meio vaginal, como, quando no período menstrual ou após ejaculações (FONSECA; REZENDE; FERNANDES, 2012).

Por tratar-se de desequilíbrio da microbiota e por apresentar frequentemente características inflamatórias pouco expressivas, foi nomeada de vaginose bacteriana, ao invés de vaginite. Importante causa de queixa em consultórios ginecológicos, podendo chegar a mais de $60 \%$ das queixas de corrimento genital, apresenta papel social significativo, já que o odor desagradável pode constranger as mulheres nos seus momentos de intimidade. Em $50 \%$ dos casos, podem não apresentar sintomas, 0 que faz crer que o odor deve-se a erro de higiene e, muitas vezes, faz a mulher lavar não somente a genitália externa, mas também o canal vaginal, agravando o quadro (FARO; SOPER, 2001; HOFFMAN et al., 2014). Quando não tratada, pode evoluir para cura espontaneamente, porém relaciona-se com maior ocorrência de parto prematuro, aminionite, endometrite pós-parto, infecção pós-cesariana, doença inflamatória pélvica e infecções pós-operatórias em ginecologia (FREITAS et al., 2011).

Às vezes, dado o constrangimento do sintoma (odor de peixe), este pode ser omitido da queixa. Ao exame clinico, porém, encontra-se uma vagina sem sinais inflamatórios que pode ou não conter um corrimento cinzento ou com microbolhas e que, ao ser recolhido e lhe instilado hidróxido de potássio a $10 \%$ (KOH 10\%), exala odor de "peixe" inconfundível. Observa-se também um pH vaginal maior do que 4,5 e, na microscopia a fresco, células pista ou clue-cells. (HALBE, 2000; FREITAS et al., 2011).

Clinicamente, o diagnóstico deve conter três dos quatro critérios propostos por Amsel et al., em 1983 (apud ELEUTÉRIO, 2005, p. 220):

a. Corrimento fino e homogêneo;

b. Teste de aminas positivo (KOH $10 \%)$;

c. $\mathrm{pH}>4,5$;

d. Microscopia a fresco com clue-cells. 
O escore de Nugent et al. (1991) é um sistema utilizado mais em pesquisa do que na prática clínica, de análise microscópica de esfregaço de secreção vaginal corada pelo Gram para diagnosticar vaginose bacteriana. A pontuação é calculada avaliando-se a predominância de três tipos de morfologia e coloração bacteriana: (1) Lactobacillus spp. (grandes bacilos gram-positivos); (2) Gardnerella vaginalis e espécies de Bacteroides (bacilos curtos gram-variáveis); e (3) Mobiluncus spp. (bacilos curvos gram-negativos ou variáveis). Pontuações entre 7 e 10 são indicadoras de vaginose bacteriana (HOFFMAN et al., 2014).

\section{CONSIDERAÇõES FINAIS}

Podemos concluir que as principais espécies de lactobacilos encontrados no canal vaginal de mulheres em idade reprodutiva são: $L$. crispatus, $L$. jensenii, $L$. gasseri e $L$. vaginalis. Essas espécies podem sofrer variações quantitativas e qualitativas entre grupos étnicos raciais diferentes.

As funções protetoras exercidas pelos lactobacilos na vagina consistem em produzir acido lático, bacteriocinas, peróxido de hidrogênio, bissurfactantes e outras substâncias que lhe permitem competir por espaço, nutrientes e receptores com outros micro-organismos potencialmente patogênicos.

O Lactobacillus crispatus se destaca não somente por ser o mais prevalente entre mulheres saudáveis com idade reprodutiva, mas também por ser um dos maiores produtores de acido lático, 0 que determina o seu maior efeito protetor contra infecções. 0 seu estudo e quantificação pode servir como biomarcador de saúde vaginal e também demonstra bom desempenho, quando usado como probótico no tratamento e prevenção da vaginose. Entretanto, outros estudos são necessários para confirmar seu benefício no tratamento da vaginose. 


\section{REFERÊNCIAS}

BROLAZO, E. M. et al. Prevalência e caracterização de espécies de lactobacilos vaginais em mulheres em idade reprodutiva sem vulvovaginites. Rev Bras Ginecol Obstet, v. 31, n. 4, p. 189-195, 2009.

BROOKS, G. F. et al. Microbiologia médica de Jawetz, Melnick e Adelberg. 25. ed. Porto Alegre: Editora AMGH, 2012.

BROTMAN, R. M. Vaginal microbiome and sexually transmitted infections: an epidemiologic prespective. The journal of clinical investigation, v. 121, n. 12, p. 4610-4617, 2011.

ELEUTÉRIO, J. Vaginose bacteriana. É a falta de infiltrado inflamatório vaginal um fator importante? RBAC, v. 37, n. 4, p. 219-221, 2005.

FARO, S.; SOPER, D. E. Infectious diseases in women. Pennsylvania: Editora W.B. Saunders Company, 2001.

FONSECA, E. C.; REZENDE, A. C. S.; FERNANDES, R. L. Corrimentos Vaginais. In: SOGIMIG. Manual de ginecologia e obstetrícia SOGIMIG. Belo Horizonte: Editora Coopmed, 2012. p. 343-350.

FREITAS, F. et al. Rotinas em ginecologia. 6. ed. Porto Alegre: Editora Artmed, 2011.

GIRALDO, P. C. et al. Influência da frequência de coitos vaginais e da prática de duchas higiênicas sobre o equilíbrio da microbiota vaginal. Rev Bras Ginecol Obstet, v. 27, n. 5, p. 257-262, 2005.

HALBE, H. W. Tratado de ginecologia. 3. ed. São Paulo: Editora Roca, 2000.

HERMMERLING, A. et al. Phase 2a study assessing colonization efficiency, safety, and acceptability of Lactobacillus crispatus CTV-05 in women with bacterial vaginosis. Sexually Transmitted Diseases, v.37 n.12 p. 745-750, 2010.

HOFFMAN, B. L. et al. Ginecologia de Williams. 2. ed. Porto Alegre: Editora AMGH, 2014.

LAMONT, R. F. et al. The microbiome: new information about genital tract flora using molecular based techniques. BJOG, v. 118, n. 5, p. 533-549, 2011.

LINHARES, I. M.; GIRALDO, P. C.; BARACAT, E. C. Novos conceitos sobre a flora bacteriana vaginal. Rev Assoc Med Bras, v. 56, n. 3, p. 370-374, 2010.

MACHADO, A.; JEFFERSON, K. K.; CERCA, N. Interactions between Lactobacillus crispatus and Bacterial Vaginosis (BV)-Associated Bacterial Species in Initial Attachment and Biofilm Formation. International Journal of Molecular Sciences, v.14 p. 12004-12012, 2013.

MARTíNEZ, W. M. Actualización sobre vaginosis bacteriana. Revista Cubana de Obstetricia y Ginecología, v. 39, n. 5, p. 427-441, 2013.

MASTROMARINO, P.; VITALI, B.; MOSCA, L. Bacterial vaginosis: review on clinical trials with probiotics. New Microbiologica, n. 36, p. 229-238, 2013.

MOORE, K. L.; DALLEY, A. F.; AGUR, A. M. R. Anatomia orientada para a clínica. 6. ed. Rio de Janeiro: Editora Guanabara Koogan, 2011. 
PETROVA, M. I. et al. Lactobacillus species as biomarkers and agents that can promote various aspects of vaginal health. Frontiers in Physiology, v.6, n.81, p. 1-18, 2015.

RAVEL, J. et al. Vaginal microbiome of reproductive-age women. PNAS, v. 108, sup. 1 p. 4680-4687, 2011.

RIBEIRO, L. F. N.; DUTRA, P. A.; GALIARDO, G. I. Anatomia e Histologia dos Órgãos Genitais Femininos. In: SOGIMIG. Manual de ginecologia e obstetrícia SOGIMIG. Belo Horizonte: Editora Coopmed, 2012. p. 03-11.

SILVA, C. H. P. M.; NEUFELD, P. M. Bacteriologia e micologia para o laboratório clínico. Rio de Janeiro: Editora Revinter, 2006.

SOARES, H. M. et al. Comparative functional genomics of Lactobacillus spp. reveals possible mechanisms for specialization of vaginal lactobacilli to their environment. Journal of bacteriology, v. 196, n. 7, p. 1458-1470, 2014.

TESTUT, L.; LATARJET, A. Anatomía humana. Barcelona: Editora Salvat, 1986.

WANDERLEY, M. S. et al. Vaginose bacteriana em mulheres com infertilidade e em menopausadas. RBG0, v. 23, n. 10, p. 641-646, 2001. 